\title{
Analysis of plant growth promoting potential of endophytes isolated from Echinacea purpurea and Lonicera japonica
}

\author{
H. Gupta ${ }^{1}$, R.V. Saini ${ }^{1}$, V. Pagadala ${ }^{2}$, N. Kumar ${ }^{3}$, D.K. Sharma ${ }^{3}$, A.K. Saini ${ }^{1, *}$ \\ ${ }^{1}$ Shoolini University of Biotechnology and Management Sciences, Faculty of Applied Sciences and Biotech- \\ nology , Bajhol, Solan, H.P., India, ${ }^{2}$ Department of Chemical Biology and Medicinal Chemistry, Eshelman \\ School of Pharmacy, University of North Carolina, Chapel Hill, NC. USA, ${ }^{3}$ CSIR-Institute of Microbial Tech- \\ nology, Sector 39A, Chandigarh, India*Corresponding author: sainiade@gmail.com
}

\begin{abstract}
Plant endophytes help in maintaining plant health by means of their biofertilizer and biocontrol attributes and, are currently being explored for their ability to produce novel biologically active compounds. Herein, we have isolated beneficial endophytic bacteria from Echinacea purpurea (EF.B3) and Lonicera japonica (LS.B11) that showed phosphate solubilization, siderophore, indole acetic acid and hydrogen cyanide production, and fixation of atmospheric nitrogen. Additionally, the endophytes also conferred antifungal activity against Fusarium sp., Rhizoctonia sp., Pythium sp. and Alternaria sp. When tested in plantae, the LS.B11 and EF.B3 strains were able to promote plant growth and control fungal infections in pea seedlings. Both strains were found to be endophytic as tested by RAPD and viability count. Based on 16S rRNA gene sequencing, we show that the LS.B11 and EF.B3 strains are related to Pseudomonas sp. and Burkholderia sp. By using degenerate primers, we identified genes related to polyketide synthases and non-ribosomal peptide synthetases in EF.B3 and LS.B11, respectively that are typically involved in the production of antimicrobial compounds. Therefore, we conclude that both endophytes can be used for increasing agriculture productivity and in the production of antimicrobial compounds for crop improvement.
\end{abstract}

Keywords: Burkholderia, antifungal, Fusarium sp, Echinacea purpurea, endophytes

\section{Introduction}

Endophytic bacterial species establish a mutualistic association with the host plant and stimulate growth, health and productivity of plant by serving as biofertilizer and biocontrol agents (Hurek and Hurek, 2011). The biofertilizer activity of endophytic bacteria is attributed to their ability to produce regulators of plant growth such as auxins, cytokinins and gibberellins. Endophytes Auxins, also help in phosphorus solubilization (Rosenblueth and Romero, 2006), nitrogen fixation, and the suppression of stress-related ethylene synthesis in plants, through the production of 1-aminocyclopropane-1-carboxylate deaminase (Hardoim et al., 2008). Endophytes confer biocontrol activity 
by protecting plants against pathogens through inducing the plant's defense mechanisms, producing pathogen-antagonizing substances (ex. hydrogen cyanide ( $\mathrm{HCN})$, siderophores, antibiotics and insecticidal compunds) or by competing with pathogenic organisms for colonization sites and nutrients (Rosenblueth and Romero, 2006).

The antimicrobial bioactivity of endophytes might be contributed by endophyte-derived secondary metabolites. These secondary metabolites are low molecular weight compounds with diverse structures and include polyketides, amino acid-derived compounds or terpenes (Keller et al., 2005). Polyketides, which are biosynthesized by large multimodular enzyme complexes termed polyketide synthases (PKS) (Keller et al., 2005), are short chain carboxylic acids usually derived from the condensation of acetyl coenzyme A (acetyl CoA) and malonyl CoA leading to the formation of carbon chains of $\beta$-ketone groups. PKSs from the endophytic bacteria Pseudomonas fluorescens Q2-87 have been shown to synthesize 2,4-diacetylphloroglucinol, which has been shown to be active against plant pathogens (Alvin et al., 2014). The type-I class of PKS from Aspergillus nidulans is involved in the production of lovastatin, a cholesterol lowering compound (Keller et al., 2005). In addition to PKSs, endophytes have also been shown to produce non-ribosomal peptides that are synthesized by large multimodular enzymes termed non-ribosomal peptide synthetases (NRPS) that help in the condensation of proteinogenic and non-proteinogenic amino acids. The first identified fungal NRPS, $\delta$-(1- $\alpha$-aminoadipyl)-1-cysteinyl-dvaline synthetase, was shown to catalyze the reaction involved in the biosynthesis of $\beta$-lactam antibiotics such as penicillin and cephalosporin (Keller et al., 2005). NRPSs from endophytes of orchids and grass crops, including Herbaspirillum seropedicae, Streptosporangium oxazolinicum and Pseudomonas aeruginosa, have been shown to produce serobactin, spoxazomicins and siderophores, respectively (Brader et al., 2014).

Miller et al., (2012) demonstrated that screening for the presence of biosynthetic genes related to PKS or NRPS may be an effective initial step in identifying the potential of bacterial endophytes to produce bioactive secondary metabolites (Miller et al., 2012). PKS and NRPS gene products contain conserved regions that are essential for the function of these enzymes. The adenylation (A) domain of NRPS, which recognizes the growing peptide chain, and the $\beta$-ketoacyl synthase (KS) domain of PKS, which assists in the condensation of acetyl CoA and malonyl CoA, are conserved (Keller et al., 2005). Therefore, phylogenetically conserved regions within the A and KS domains could be targeted by using degenerate oligonucleotide primers in order to detect the NRPS and PKS biosynthesis genes, respectively, and in turn for genetic screening of endophytes with the potential to produce bioactive compounds that can be used for crop improvement.

In this study, two bacterial endophytes from the medicinal plants Echinacea purpurea and Lonicera japonica were isolated. Their endophytic nature was confirmed by viability counts in pea seedlings and by (Random amplified polymorphic DNA) RAPD analysis. We found that the endophytes conferred both biocontrol and biofertilizer activities on the host plants. Seed inoculation experiments confirmed that the Burkholderia sp. and Pseudomonas sp. as endophytes could be used as growth promoting agents and could control phytopathogens in plantae. Moreover, we found that these strains contained the NRPS and PKS genes, 
which supports their potential for the production of useful secondary metabolites.

\section{Materials and Methods}

\subsection{Selection and collection of plant samples}

Plant extracts of Echinacea purpurea and Lonicera japonica confer antimicrobial (Hudson, 2011) and antiinflammatory activities (Chen et al., 2012). The leaves, roots, stems and flower-petals of these medicinal plants were collected from the Botanical Garden of Shoolini University, Solan (Himachal Pradesh). Plant parts were collected in sterile bags and processed further. One set of each plant part was autoclaved and was processed as a control.

\subsection{Surface sterilization of plant samples}

Plant parts were washed in running tap water followed by distilled water. Surface sterilization of the plant material was achieved by immersing it in $70 \%$ ethanol for $1 \mathrm{~min}$ and then in sodium hypochlorite for $3 \mathrm{~min}$, followed by washing with $70 \%$ ethanol for $30 \mathrm{sec}$ and finally, washing with autoclaved distilled water for $10 \mathrm{~min}$ and process was repeated thrice (Favaro et al., 2012). To assess surface sterilization, the last wash was plated on nutrient agar and incubated at $30^{\circ} \mathrm{C}$ for $72 \mathrm{~h}$.

\subsection{Isolation of endophytes}

Surface sterilized plant parts were weighed and macerated using a pestle and mortar in the presence of phosphate buffered saline (PBS; $0.8 \%$ $\mathrm{NaCl}, 0.02 \% \mathrm{KCl}, 0.144 \% \mathrm{Na}_{2} \mathrm{HPO}_{4}, 0.024 \% \mathrm{KH}-$ $\left.{ }_{2} \mathrm{PO}_{4}\right)(1 \mathrm{ml}$ per $\mathrm{g}$ of plant part). The mixture was centrifuged at $1,000 \mathrm{rpm}$ for $3 \mathrm{~min}$. Supernatant was collected and again centrifuged at 10,000 rpm for $10 \mathrm{~min}$. Supernatant was discarded and the pellet was obtained. The pellet was resuspended in 1 $\mathrm{ml}$ PBS (Kang et al., 2007) and serial dilutions were plated to enumerate the colony forming units (CFU). Briefly, $100 \mu 1$ of suspension was plated on nutrient agar medium (NAM) and incubated at $30{ }^{\circ} \mathrm{C}$ for 72 h. Isolates from NAM plates were further analyzed for their ability to confer biofertilizer and biocontrol activities.

\subsection{Biofertilizer activities}

Pikovskaya's agar medium was used to analyze inorganic phosphate solubilization, as described previously (Trivedi et al., 2011). Formation of a halo zone around the bacterial colonies was taken as an indicator of phosphate solubilization. The halo zone was calculated by subtracting the colony diameter from the total diameter. For quantitative estimation of phosphate solubilization, endophytes were inoculated in $5 \mathrm{ml}$ of Pikovskaya media and incubated at $30^{\circ} \mathrm{C}$ for 4 days. The bacterial culture was then centrifuged at $12,000 \mathrm{rpm}$ for $20 \mathrm{~min}$ to collect the supernatant. Then, $2 \mathrm{ml}$ of chloromolibidic acid $(1.5 \%$ in $10 \mathrm{~N} \mathrm{HCl}), 100 \mu 1$ of chlorostannous acid $(0.2 \mathrm{~g}$ in $5 \mathrm{ml}$ conc. $\mathrm{HCl}$ and 5 $\mathrm{ml} \mathrm{H}_{2} \mathrm{O}$ ) and $10 \mathrm{ml}$ distilled water was added. The reaction mixture was kept at room temperature for 10 min after which the absorbance was measured at $600 \mathrm{~nm}$. The amount of soluble phosphorus was detected from the standard curve of $\mathrm{KH}_{2} \mathrm{PO}_{4}$ (Ahmad et al., 2008). Phytate media was used to analyze the production of phytase enzyme by the endophytes (Quan et al., 2001). Briefly, $0.5 \mu 1$ of $1 \mathrm{OD}_{600}$ bacterial cells $\left(\sim 10^{5}\right.$ cells $)$ were spotted on phytate agar media $(1.5 \%$ glucose, $0.5 \%$ $\left(\mathrm{NH}_{4}\right)_{2} \mathrm{SO}_{4}, \quad 0.01 \% \quad \mathrm{MgSO}_{4} \cdot 7 \mathrm{H}_{2} \mathrm{O}, \quad 0.01 \% \mathrm{NaCl}$, $0.01 \% \quad \mathrm{CaCl}_{2} .2 \mathrm{H}_{2} \mathrm{O}, \quad 0.001 \% \quad \mathrm{FeSO}_{4}, \quad 0.001 \%$ $\mathrm{MnSO}_{4}, 0.25 \%$ calcium phytate, $2 \%$ agar, $\mathrm{pH} 7.0$ ) 
and incubated at $30{ }^{\circ} \mathrm{C}$ for 3 days. Phytase production was identified by formation of a halo zone around the bacterial colony.

$\mathrm{N}_{2}$ fixing ability of bacterial endophytes was examined by testing their ability to grow on nitrogen-free semisolid BAz medium (Devi et al., 2015). BAz media $\left(0.2 \%\right.$ azelaic acid, $0.04 \% \mathrm{~K}_{2} \mathrm{HPO}_{4}, 0.04 \%$ $\mathrm{KH}_{2} \mathrm{PO}_{4}, 0.02 \% \mathrm{MgSO}_{4} .7 \mathrm{H}_{2} \mathrm{O}, 0.002 \% \mathrm{CaCl}_{2} .2 \mathrm{H}_{2} \mathrm{O}$, $0.0002 \% \mathrm{Na}_{2} \mathrm{MoO}_{4} \cdot \mathrm{H}_{2} \mathrm{O}, 0.001 \% \mathrm{FeCl}_{3}, 0.0075 \%$ bromothymol blue and 2\% agar, $\mathrm{pH} 5.7$ adjusted with $\mathrm{KOH})$ was autoclaved and then supplemented with filter-sterilized cycloheximide $(4 \mathrm{mg} / 100 \mathrm{ml})$. Isolates were patched on BAz media and growth was monitored at $30{ }^{\circ} \mathrm{C}$. We also tested the endophytes for their capacity to produce ammonia. For this, cells were grown in $10 \mathrm{ml}$ peptone water (peptone $10 \mathrm{~g} / \mathrm{l}$ in $5 \mathrm{~g} / 1 \mathrm{NaCl}$ ) for $72 \mathrm{~h}$ at $30{ }^{\circ} \mathrm{C}$. Later, $0.5 \mathrm{ml}$ Nessler's reagent was added to the culture tubes and the color change was observed. Transformation of brown color into yellow color was taken as a positive test for ammonia production (Ahmad et al., 2008).

The production of the phytohormone indole-3-acetic acid (IAA) by bacterial endophytes was analyzed and quantified using the Salkowski assay, as described previously (Ahmad et al., 2008). Briefly, strains were grown in $5 \mathrm{ml}$ nutrient broth medium supplemented with L-tryptophan $\left(200 \mu \mathrm{g} \mathrm{ml}^{-1}\right)$ for $72 \mathrm{~h}$ at $30^{\circ} \mathrm{C}$ with shaking at $250 \mathrm{rpm}$. After $72 \mathrm{~h}$, culture supernatants were obtained by centrifugation at $6,000 \times \mathrm{g}$ for $10 \mathrm{~min}$ and $500 \mu \mathrm{l}$ of supernatant was mixed with $500 \mu \mathrm{l}$ of Salkowski's reagent $\mathrm{R} 1\left(\mathrm{FeCl}_{3}\right.$, $12 \mathrm{~g} / \mathrm{l}$ in $42.9 \% \mathrm{v} / \mathrm{v} \mathrm{H}_{2} \mathrm{SO}_{4}$ ) and incubated in the dark for $20 \mathrm{~min}$. The absorbance at $535 \mathrm{~nm}$ was determined. The concentration of IAA was calculated using standard curves created with purified IAA.

\subsection{Biocontrol activities}

The production of siderophores by bacterial endophytes was analyzed by observing the ability of the strains to produce an orange halo zone on Chrome azurol S agar (CAS-agar) media (0.33 mM Chrome azurol $\mathrm{S}$ dye, $2.47 \mathrm{mM} \mathrm{FeCl}{ }_{3} .6 \mathrm{H}_{2} \mathrm{O}, 0.36 \mathrm{mM}$ $\mathrm{N}, \mathrm{N}, \mathrm{N}, \mathrm{N}-\mathrm{Cetyl}$ trimethyl ammonium bromide, $0.33 \mathrm{mM} \mathrm{HCl}, 42.23 \mathrm{~g} / 1$ King's B base) as described previously (Schwyn and Neilands, 1987). Briefly, strains were inoculated in $5 \mathrm{ml}$ nutrient broth media and grown at $30{ }^{\circ} \mathrm{C}$ until the $\mathrm{OD}_{600}$ reached 1 . Then, $2 \mu 1$ of these cells were spotted on CAS-agar media. Cells were incubated at 30 ${ }^{\circ} \mathrm{C}$ and observed for the formation of orange halos around the spotted culture. Halo size was measured by subtracting the diameter of the colony from the total diameter (Colony and halo diameter). For quantitative estimation of siderophore production, cultures were grown in Chrome azurol $\mathrm{S}$ liquid medium (CAS-liquid) (0.33 mM Chrome azurol $\mathrm{S}$ dye, $2.47 \mathrm{mM} \mathrm{FeCl}_{3} .6 \mathrm{H}_{2} \mathrm{O}, 0.36 \mathrm{mM} \mathrm{N}, \mathrm{N}, \mathrm{N}, \mathrm{N}-$ cetyl trimethyl ammonium bromide, $0.33 \mathrm{mM} \mathrm{HCl}$, $13 \mathrm{~g} / 1$ nutrient broth) at $30{ }^{\circ} \mathrm{C}$ for 3 days at 150 rpm. The supernatant was collected by centrifugation at 10,000 rpm for $10 \mathrm{~min}$ and was analyzed by spectrophotometer at $630 \mathrm{~nm}$ (Schwyn and Neilands, 1987). Strains were also analyzed for their ability to produce hydrogen cyanide (Ahmad et al., 2008). For this, cells were streaked on modified nutrient agar medium supplemented with glycine $(4.4 \mathrm{~g} / \mathrm{l})$. A Whatman filter paper no. 1 soaked in $2 \%$ sodium carbonate in $0.5 \%$ picric acid solution was placed such that it covered the agar medium without touching the top surface of the growing cells. Plates were sealed with parafilm and incubated at $30{ }^{\circ} \mathrm{C}$ for 4 days. Development of an orange to red color indicated $\mathrm{HCN}$ production.

The strains were further tested for in vitro antagonism of the plant pathogenic fungi Fusarium sp., Rhizoctonia sp., Pythium sp. and Alternaria sp. (Source: Microbial Type Culture Collection, Institute of Microbial Technology, Chandigarh, India). 
Fungi were grown on potato dextrose agar (PDA) medium and later a disc of $4.5 \mathrm{~mm}$ radius was excised and placed on a separate PDA media. Bacterial strains were streaked at $2 \mathrm{~cm}$ away from the fungal disc and incubated at $25^{\circ} \mathrm{C}$. The percentage zone of inhibition was calculated by measuring (C$\mathrm{T}) / \mathrm{Cx} 100$, where "C" is the average diameter of fungal growth in the control and " $\mathrm{T}$ " is the average diameter of fungal growth in the treatment.

\section{6. Seedling experiments}

We also tested the ability of endophytes to promote plant growth using seedlings of Pisum sativum (commonly called the pea). The pea seeds were surface sterilized, as described above, and were allowed to grow in the dark for $\sim 6$ days at $25^{\circ} \mathrm{C}$ under moist conditions until they began germinating. Germinated seeds were soaked in $50 \mathrm{ml}$ bacterial culture suspension $\left(1 \mathrm{OD}_{600}\right)$ for 10 minutes. After 15 days of treatment, the seedlings were analyzed for their root length, shoot length, number of lateral roots, fresh weight and dry weight. Similarly, to determine whether the bacterial strains could ameliorate the negative effects of phytopathogenic fungi on germinated seeds, the seedlings were first treated for 10 min with either a fungal suspension (which was obtained after growing the phytopathogenic fungi for five days in potato dextrose broth) or broth alone. Seedlings were later treated with either $50 \mathrm{ml}$ of bacterial culture suspension (1 $\mathrm{OD}_{600}$ ) for 10 minutes or with nutrient broth alone. The seeds were incubated at $25^{\circ} \mathrm{C}$ for 15 days. For each experiment, 100 seeds were tested.

\subsection{Statistical analysis}

Each experimental treatment was replicated four times. A column t-test was performed to compare means. The t-test was performed between the values in the columns for similar numbered rows. Analysis of the data was carried out using Graphpad prism version 9.2 (SAS Institute Inc., Cary, NC, USA) with a completely randomized analysis of variance $(p<0.05)$. The $\mathrm{p}$ values were determined by Student t-test (two-tailed, paired/unequal variances).

\subsection{DNA extraction and identification of PKS- and NRPS-containing strains}

Genomic DNA was isolated from bacterial endophytes using a DNA purification kit (Zymo Research) as per the manual. Degenerate primers were used to amplify the KS domain of the PKS gene or the A domain of the NRPS gene (Miller et al., 2012). The primers DKF (5'-GCGCGGAATTCGTGCCGGTNCCRTGNGYYTC-3') and DKR (5'-GCGCGCAAGCTTGCGATGGAYCCNCARCARMG-3') were used to amplify the KS domain and MTF2 (5'-GCGCGGAATTCGCNGGYGGYGCNTAYGTNCC-3') and MTR2 (5'-GCGCGCAAGCTTCCNCGDATYTTNACYTG-3') were used to amplify the A domain (Miller et al., 2012). PCR reactions were carried out in a $10 \mu 1$ reaction volume containing $1 \mathrm{ng} / \mu \mathrm{l}$ genomic DNA, 5 $\mathrm{mM} \mathrm{MgSO}_{4}, 0.2 \mathrm{mM}$ dNTPs, $1 \mu \mathrm{M}$ each primer, 0.4 U Taq Hifi (Invitrogen) and 1X Taq Hifi buffer. Thermal cycling was carried out with an initial denaturation at $95{ }^{\circ} \mathrm{C}$ for $2 \mathrm{~min}$, followed by 35 cycles of $95{ }^{\circ} \mathrm{C}$ for $30 \mathrm{sec}, 52{ }^{\circ} \mathrm{C}$ (for A domain) or $55{ }^{\circ} \mathrm{C}$ (for KS domain) for $30 \mathrm{sec}, 72{ }^{\circ} \mathrm{C}$ for $1 \mathrm{~min}$, followed by a final extension at $72{ }^{\circ} \mathrm{C}$ for $10 \mathrm{~min}$. PCR amplicons were analyzed on a $1 \%$ agarose gel. The amplicons were later extracted from the agarose gel and purified using the QIAquick Gel Extraction Kit (Qiagen, Hilden, Germany). The PCR products were cloned into a pGEM-T Easy 
Vector (Promega Corp.) using the manufacturer's protocol. Transformants were selected on LB agar medium complemented with ampicillin $(100 \mu \mathrm{g}$ $\mathrm{ml}^{-1}$ ), isopropyl- $\beta$-D-thiogalactopyranoside (200 $\mu \mathrm{g} \mathrm{ml}^{-1}$ ) and 5-bromo-4-chloro-3-indolyl- $\beta$-Dgalactopyranoside $\left(200 \mu \mathrm{g} \mathrm{ml}^{-1}\right)$. White colonies were selected and grown in LB medium complemented with ampicillin at a final concentration of $100 \mu \mathrm{g} \mathrm{ml}^{-1}$ at $37^{\circ} \mathrm{C}$ for $24 \mathrm{~h}$. Plasmids were isolated from transformants using the QiaPrep Spin Miniprep kit (Qiagen, Germany). Thereafter, the plasmids were sequenced using the $\mathrm{T} 7$ forward primer (5'-TAATACGACTCACTATAGGG-3').

\subsection{Phylogenetic analysis}

The experimentally obtained DNA sequences of the A or KS domains were compared with the sequences listed by the GenBank databases using the basic local alignment search tools (BLAST) software provided online by the National Center for Biotechnology Information (USA). Evolutionary relationships of the sequenced $\mathrm{KS}$ and A fragments were determined by maximum likelihood analysis using the Jones-Taylor-Thornton (JTT) model and the phylogenetic analysis was conducted in MEGA package version 6 .

\subsection{0. $16 \mathrm{~S}$ rRNA gene sequencing}

Isolated strains were characterized by sequencing their 16S rRNA gene. PCR amplification of the $16 \mathrm{~S}$ rRNA gene was performed using the primers $27 \mathrm{f}$ (5'-GCGCGGAATTCAGAGTTTGATCCTGGCTCAG-3') and 1492 rev (5'-GCGCGCAAGCTTGGTTACCTTGTTACGACTT-3') (Trivedi et al., 2011). Thermal cycling for $16 \mathrm{~S}$ involved an initial denaturation at $95{ }^{\circ} \mathrm{C}$ for $2 \mathrm{~min}$, followed by 30 cycles of $95{ }^{\circ} \mathrm{C}$ for $30 \mathrm{sec}, 54{ }^{\circ} \mathrm{C}$ for $30 \mathrm{sec}, 72^{\circ} \mathrm{C}$ for $2 \mathrm{~min}$, followed by a final extension at $72{ }^{\circ} \mathrm{C}$ for $10 \mathrm{~min}$ and a final hold at $4{ }^{\circ} \mathrm{C}$. The amplified DNA product was sequenced and the 16S rRNA sequence obtained was analyzed using the BLAST program.

\subsection{Endophytic nature of bacterial strains in plantae}

To test whether bacterial isolates were capable of colonizing inside the plants, the bacterial strains were used to treat pea seedlings and were grown aseptically under in vitro conditions as described above. At different time intervals roots and stems were weighed and excised and endophytes were isolated to enumerate the CFUs. Only colonies which showed color and colony morphology similar to the treated strain were counted (Kang et al., 2007). We randomly picked 100 colonies and their identity was confirmed by their ability to confer biofertilizer activity.We later chose two stem and two root samples for random amplified polymorphic DNA (RAPD) analysis and 16S rDNA sequencing. RAPD analysis was performed with RAPD primer 5'- CATTTTGCTGCCGGTC-3'. The randomly chosen strains were used to isolate DNA using DNA isolation kit (Zymo research). PCR reactions were carried out as described previously (Kang et al., 2007). Briefly, the reaction was carried out in a $25 \mu \mathrm{l}$ reaction volume containing $1 \mathrm{ng} / \mu \mathrm{lge}$ nomic DNA, 0.6 mM $\mathrm{MgSO}_{4}, 0.1 \mathrm{mM}$ dNTPs each, $0.2 \mu \mathrm{M}$ primer, $0.5 \mathrm{U}$ elongase enzyme (Invitrogen) and $1 \mathrm{X}$ elongase buffer. Thermal cycling for RAPD was completed with an initial denaturation at $94{ }^{\circ} \mathrm{C}$ for 4 min, followed by 45 cycles of $94^{\circ} \mathrm{C}$ for $1 \mathrm{~min}$, $37^{\circ} \mathrm{C}$ for $1.5 \mathrm{~min}, 68^{\circ} \mathrm{C}$ for $2 \mathrm{~min}$, followed by a final extension at $68^{\circ} \mathrm{C}$ for $10 \mathrm{~min}$ and a final hold at $4{ }^{\circ} \mathrm{C}$. 
PCR amplicons were analyzed on a $1.4 \%$ agarose gel and the band pattern was compared between inoculated strains and re-isolated strains.

\section{Results}

\subsection{Petals, leaves, stems and roots of E. purpurea and}

\section{L. japonica harbor endophytes}

Plant parts from E. purpurea and L. japonica were analyzed for the presence of bacterial endophytes. To remove the non-endophytes, plant parts were surface sterilized using sodium hypochlorite, macerated in PBS to release endophytes and plated on nutrient agar to estimate the endophytic bacterial count. We found that $1 \mathrm{~g}$ of E. purpurea flowers, leaves and roots yielded $150 \pm 360,970 \pm 28$ and 165 \pm 77 CFUs, respectively. Similarly, $1 \mathrm{~g}$ of L. japonica stems and flower petals resulted in $1400 \pm 100$ and $225 \pm 16$ CFUs, respectively.

3.2. Endophytes isolated from E. purpurea or L. japonica exhibit biofertilizer and biocontrol activities

Fifty randomly picked isolates from E. purpurea or L. japonica were tested for their ability to solubilize organic and inorganic phosphate and to produce siderophore. Two endophyte strains isolated from E. purpurea (EF.B2 and EF.B3) and one strain from L. japonica (LS.B11) formed a halo zone on plates containing Pikovskaya medium or calcium phytate indicating their ability to solubilize both organic and inorganic phosphate. Furthermore, we found that EF.B3, EF.B5, EF.B7, EL.B5 and EL.B11 isolates from E. purpurea, and LS.B1, LS.B8, LS.B11 and LS.B12 from L. japonica produced siderophores as indicated by the formation of an orange halo zone in CAS-agar.
Interestingly, the EF.B3 and LS.B11 isolates exhibited both phosphate solubilization and siderophore production activities, and were further analyzed for other biofertilizer and biocontrol activities.

\subsection{Phosphate solubilization}

Phosphate solubilization activity was quantified using the chlorostannous reduced molybdophosphoric acid blue method, as described previously (Ahmad et al., 2008). We found that $1 \mathrm{OD}_{600}$ of LS.B11 cells $\left(\sim 10^{8}\right.$ cells $)$ produced $569.75 \pm 43 \mu \mathrm{g} /$ $\mathrm{ml}$ and EF.B3 produced $685.5 \pm 34.7 \mu \mathrm{g} / \mathrm{ml}$ of soluble phosphate from tricalcium phosphate. Analysis of phosphate solubilization activity by LS.B11 on solid agar media carrying either inorganic phosphate (Pikovskaya media) or organic phosphate (calcium phytate) media showed halo zone diameters of $4 \pm 0.1 \mathrm{~mm}$ and $13 \pm 0.2 \mathrm{~mm}$, respectively (Figure 1a). Similarly, EF.B3 showed $9 \pm 0.2 \mathrm{~mm}$ and $14 \pm 0.3 \mathrm{~mm}$ halo zones on media containing calcium phosphate and calcium phytate, respectively (Figure 1a). As compared to previous results, the phosphate solubilizing activity of EF.B3 was found to be slightly better than that previously reported by others (Rajendran et al., 2011).

\subsection{Nitrogen fixation and ammonia production}

LS.B11 and EF.B3 were able to grow on semi-solid BAz medium without an added nitrogen source, suggesting their ability to fix atmospheric nitrogen (Figure 1b). The negative control E.coli DH5 $\alpha$ strain showed no growth on BAz media. Furthermore, EF.B3 and LS.B11 were able to produce ammonia as evidenced by the formation of a yellow color in peptone water (Devi et al., 2015). 
(a)

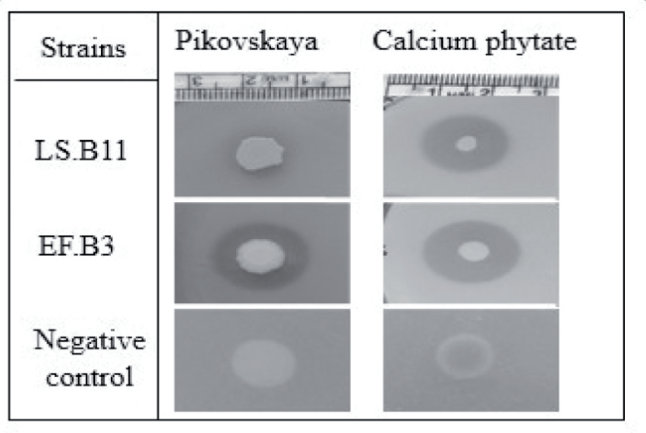

(b)

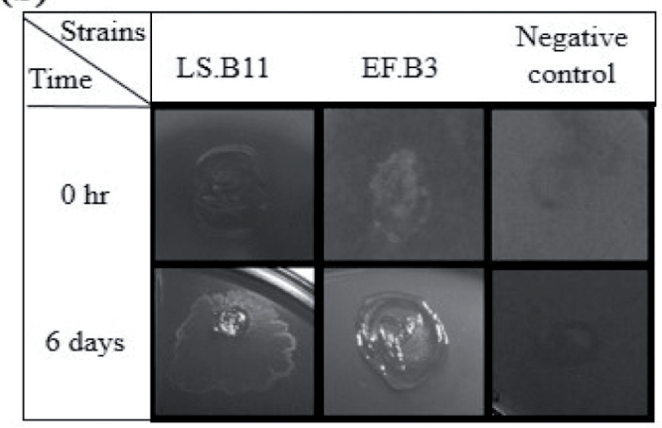

(c)

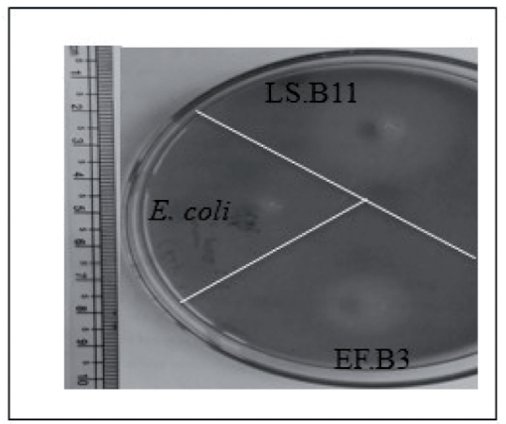

Figure 1. Biofertilizer and biocontrol activities of endophytic strains. (a) Phosphate solubilization: $0.5 \mu \mathrm{l}$ cells $\left(\mathrm{OD}_{600}=1\right)$ of LS.B11 and EF.B3 were spotted on Pikovskaya medium or calcium phytate medium. Cells were incubated for $24 \mathrm{~h}$ and the formation of a halo zone was analyzed. (b) Nitrogen fixation: bacterial cells were patched on BAz medium. Cell growth was analyzed at $0 \mathrm{~h}$ and after 6 days at $30^{\circ} \mathrm{C}$. E. coli DH5 $\alpha$ was used as a negative control. (c) Siderophore production: biocontrol activity of bacteria was analyzed by spotting $2 \mu \mathrm{l}\left(\mathrm{OD}_{600}=1\right)$ of LS.B11 or EF.B3 on CAS-agar. The formation of an orange halo was analyzed after $48 \mathrm{~h}$ at $30^{\circ} \mathrm{C}$.

\subsection{IAA production}

IAA production by endophytic bacteria is correlated with the ability of these bacteria to induce root elongation and root hair formation. We found that $1 \mathrm{OD}_{600}$ cells of LS.B 11 produced $6.5 \pm 0.3 \mu \mathrm{g} / \mathrm{ml}$ of IAA. Similarly EF .B3 produced $3.5 \pm 0.2 \mu \mathrm{g} / \mathrm{ml}$ of IAA. The levels of IAA produced by LS.B11 and EF.B3 fall in the range that was previously reported for other endophytes isolated from the roots of sugarcane plants (Luvizotto et al., 2010)

\subsection{Siderophore production}

Siderophore production has been shown to inhibit the growth of phytopathogens by limiting the availability of iron (Loper and Buyer, 1991). Siderophore production was detected by the formation of an orange zone around bacterial colonies grown on CAS-agar media. Zones of $26 \pm 0.6 \mathrm{~mm}$ for the LS.B11 strain and $16 \pm 0.5$ $\mathrm{mm}$ for the EF.B3 strain were observed (Figure 1c) suggesting their ability to chelate iron from the CAS- 
agar media (Schwyn and Neilands, 1987). Siderophore production was further quantified in CASliquid. We found that $1 \mathrm{OD}_{600}$ cells of the LS.B11 strain produced $\sim 9$ fold higher and EF.B3 produced $\sim 6$ fold higher amounts of siderophore as compared to E.coli DH5 $\alpha$. This is in agreement with the orange zone formation on CAS-agar media, which was bigger in the LS.B11 strain as compared to EF.B3 (Figure 1c).

\subsection{Hydrogen cyanide production}

The LS.B11 and EF.B3 strains showed changes in color from orange to red, indicating that both strains have the capability to produce $\mathrm{HCN}$. The negative control showed no color change suggesting no $\mathrm{HCN}$ production (Etesami et al., 2014).
3.8. In vitro antifungal activity of LS.B11 and EF.B3 against phytopathogens

The growth of Echinacea purpurea and Lonicera japonica is greatly affected by fungal diseases caused by Rhizoctonia sp., Fusarium sp., Alternaria sp. and Pythium sp. (Waipara et al., 2007). Therefore, we tested the biocontrol activities of LS.B11 and EF.B3 against fungal phytopathogens by using in vitro growth inhibition of fungal disc in the presence of endophytes. We found that the LS.B11 strain showed $75 \%, 62 \%, 53 \%$ and $54 \%$ growth inhibition against Rhizoctonia sp., Fusarium sp., Alternaria sp. and $P y$ thium sp., respectively (Figures $2 \mathrm{a}-\mathrm{d}$, Table 1 ). The EF.B3 strain showed inhibition of $71 \%, 68 \%, 71 \%$, and $61 \%$ against Rhizoctonia sp., Fusarium sp., Alternaria sp. and Pythium sp. respectively (Figures 2a-d, Table 1). These results suggest that both endophytic strains can be used as biocontrol agents.

Table 1. Percentage growth inhibition of phytopathogenic fungi by the endophytic strains LS.B11 and EF.B3.

\begin{tabular}{|c|l|c|c|}
\hline $\begin{array}{l}\text { Serial } \\
\text { No. }\end{array}$ & Fungal strain & \% inhibition by LS.B11 & $\begin{array}{l}\text { \% inhibition by } \\
\text { EF.B3 }\end{array}$ \\
\hline 1. & Rhizoctonia sp. & $75.56 \pm 3.3$ & $71.11 \pm 2.2$ \\
\hline 2. & Fusarium sp. & $62.16 \pm 2.6$ & $68.42 \pm 3.5$ \\
\hline 3. & Alternaria sp. & $53.75 \pm 3.8$ & $71.25 \pm 2.9$ \\
\hline 4. & Pythium sp. & $54.17 \pm 1.2$ & $61.1 \pm 1.8$ \\
\hline
\end{tabular}


(a)

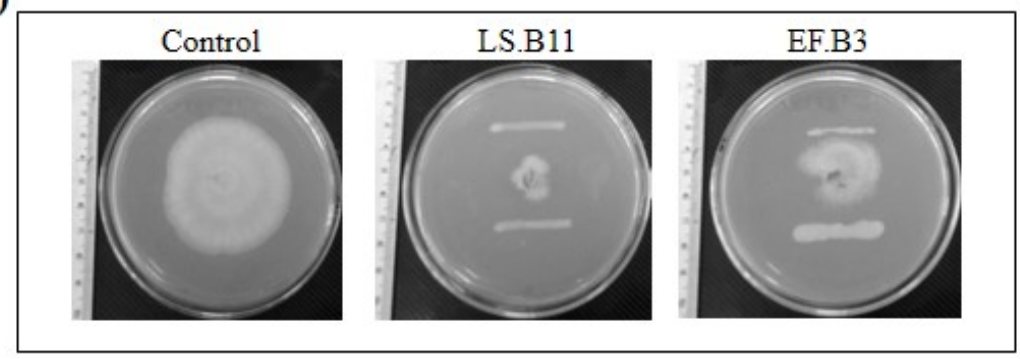

(b)

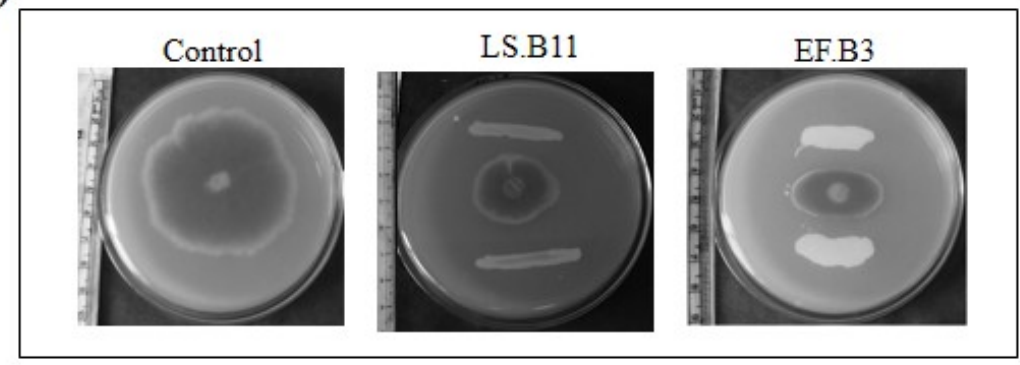

(c)

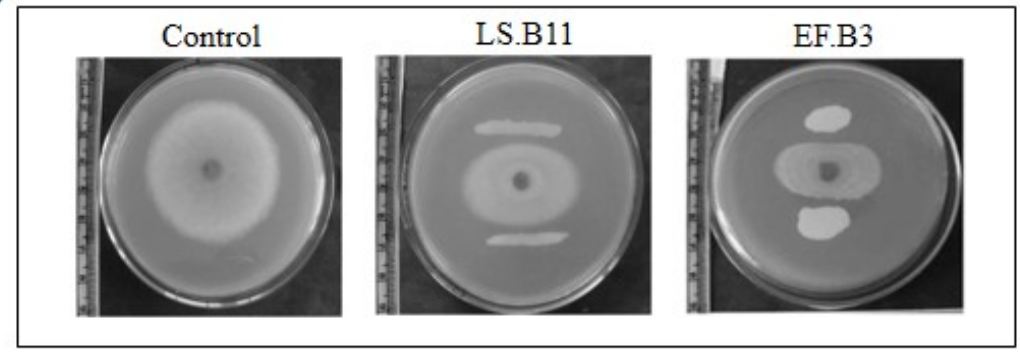

(d)

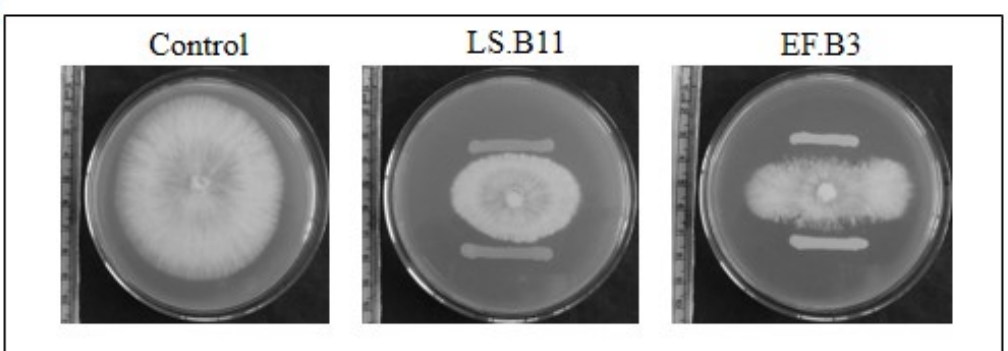

Figure 2. In vitro antifungal activity against plant pathogenic fungi. A fungal disc containing pathogenic fungi Rhizoctonia sp. (a), Fusarium sp. (b), Alternaria sp. (c) or Pythium sp. (d) was placed in the center of a plate containing potato dextrose agar. LS.B11 and EF.B3 were each streaked $2 \mathrm{~cm}$ away from the disc. Plates A, B, C and $\mathrm{D}$ were incubated for $2 \mathrm{~d}, 6 \mathrm{~d}, 5 \mathrm{~d}$ and $3 \mathrm{~d}$, respectively, at $25^{\circ} \mathrm{C}$. 


\subsection{In plantae effects of LS.B11 and EF.B3}

- Growth promotion

The presence of biofertilizer activities such as IAA production, nitrogen fixation and phosphate solubilization demonstrates that both the LS.B11 and EF.B3 strains could stimulate plant growth. Therefore, these strains were further explored for their ability to promote seedling growth. Surface sterilized pea seeds were treated with LS.B11 and EF.B3 as described in the experimental procedures. Interestingly, both LS.B11 and EF.B3 stimulated a higher rate of root and shoot formation/growth, as compared to the untreated seeds (Table 2, lanes 2 and 3 vs. 1). LS.B11 treatment increased the root length by $\sim 4$ fold and the shoot length by $\sim 1.2$ fold as compared to untreated seeds (Table 2, lane 2 vs. 1).

On the other hand, EF.B3 increased root length by $\sim 2.9$ fold and shoot length by $\sim 2$ fold (Table 2, lane 3 vs. 1). Similarly, seeds treated with LS.B11 and EF.B3 showed an $\sim 1.5$ fold increase in secondary roots as compared to untreated seeds (Table 2).

The growth promotion activities demonstrated by both endophytes confirm their symbiotic role in the host plant.

Table 2. Effect of endophytes on peaseedlings after different fungal treatments

\begin{tabular}{|c|c|c|c|c|c|c|}
\hline S.No. & Treat & $\begin{array}{l}\text { Shoot length } \\
\text { (cm) }\end{array}$ & $\begin{array}{l}\text { Root length } \\
\qquad(\mathrm{cm})\end{array}$ & $\begin{array}{l}\text { Number of } \\
\text { side roots }\end{array}$ & $\begin{array}{l}\text { Fresh wt. of } \\
\text { seedling (g) }\end{array}$ & $\begin{array}{l}\text { Dry wt. of } \\
\text { seedling (g) }\end{array}$ \\
\hline 1. & Intres & $9^{b}$ & $3 \pm 0$ & & 0.7 & $.023^{\mathrm{a}}$ \\
\hline 2. & LS.B11 & 278,007 a & $12.8 \pm 0.95^{\mathrm{a}}$ & $29 \pm 3.74^{\mathrm{a}}$ & $b^{b}$ & $0.138 \pm 0.010^{\mathrm{a}}$ \\
\hline 3. & (DJ & & & & & \\
\hline 4. & Fusar & $3.3 \pm 0$. & 4 & - & $0.516=$ & $0.011^{\mathrm{a}}$ \\
\hline 5. & isar & $9 / 2 \pm$ & 10.33 & $7^{\mathrm{a}}$ & 0.140 & $017^{\mathrm{a}}$ \\
\hline 6. & usariu & $5.08 \pm 1.137^{\mathrm{a}}$ & $8 \pm$ & $5^{\mathrm{a}}$ & a & $1^{\mathrm{a}}$ \\
\hline 7. & 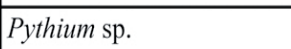 & $\overline{4 \pm}$ & $1.82 \pm 0.540^{\mathrm{b}}$ & $1 \pm 0$. & $0.613 \pm 0.045^{a}$ & $0.115 \pm 0.018^{\mathrm{a}}$ \\
\hline 8. & Pythiu & $4.9 \pm 0.459^{\prime \prime}$ & $9.57 \pm$ & $26 \pm 3.26^{a}$ & 0.798 & $.025^{b}$ \\
\hline 9. & Pythiu & $2.4 \pm 0.589^{b}$ & $10.7 \pm 0.56^{\mathrm{a}}$ & $a c^{-b}$ & $6^{\mathrm{a}}$ & $0.129 \pm 0.025^{b}$ \\
\hline 10. & $i z$ & 375 & $1.28 \pm$ & 1.6 & 0.52 & $.008^{b}$ \\
\hline 11. & Rhizoctonia sp. + LS.B11 & $4.4 \pm 0.316^{\mathrm{a}}$ & $9.22 \pm 0.35^{\mathrm{a}}$ & $32.8 \pm 1.92^{\mathrm{a}}$ & $0.758 \pm 0.018^{\mathrm{a}}$ & $0.125 \pm 0.001^{\mathrm{a}}$ \\
\hline 12. & Rhizoctonia sp. + EF.B3 & 3.35 & $8.2 \pm$ & $20.2 \pm 2$ & 0.73 & 0.11 \\
\hline 13. & Alternaria sp. & $4.1 \pm 0.55^{\mathrm{a}}$ & $0.982 \pm 0.394^{\mathrm{a}}$ & $12 \pm 1.64^{\mathrm{a}}$ & $0.661 \pm 0.096^{\mathrm{a}}$ & $0.117 \pm 0.017^{\mathrm{a}}$ \\
\hline 14. & + LS.B11 & $4.511 \pm 0.165^{\mathrm{a}}$ & $6.84 \pm 0.27^{\mathrm{a}}$ & $27.2 \pm 2.28^{\mathrm{a}}$ & $0.777 \pm 0.061^{\mathrm{a}}$ & $0.140 \pm 0.012^{\mathrm{a}}$ \\
\hline 15. & E.B3 & $5.6 \pm 1.134^{\mathrm{b}}$ & $5.405 \pm 0.066^{\mathrm{a}}$ & $20.67 \pm 3.07^{\mathrm{a}}$ & $0.864 \pm 0.076^{\mathrm{a}}$ & $0.137 \pm 0.006^{\mathrm{a}}$ \\
\hline
\end{tabular}


Pea seedlings were treated and the average obtained from four replicates with 25 seedlings for each treatment is shown with standard error. Lane 1: untreated seeds (control); Lane 2: seeds treated with LS.B11; Lane 3: seeds treated with EF.B3; Lane 4 seeds treated with Fusarium sp.; Lane 5: seeds treated with Fusarium sp. and LS.B11; Lane 6: seeds treated with Fusarium sp. and EF.B3; Lane 7: seeds treated with Pythium sp.; Lane 8: seeds treated with Pythium sp. and LS.B11; Lane 9: seeds treated with Pythium sp. and EF.B3; Lane 10: seeds treated with Rhizoctonia sp.; Lane 11: seeds treated with Rhizoctonia sp. and LS.B11; Lane 12: seeds treated with Rhizoctonia sp. and EF.B3; Lane 13: seeds treated with Alternaria sp.; Lane 14: seeds treated with Alternaria sp. and LS.B11, Lane 15: seeds treated with Alternaria sp. and EF.B3.

Values are mean \pm standard deviation of four replicates with 25 seedlings for each treatment. For each column, values in row 1 are compared with rows 2 or 3 ; row 4 is compared with 5 or 6 ; row 7 is compared with 8 or 9 ; row 10 is compared with 11 or 12 and; row 13 is compared with 14 or $15 .{ }^{\mathrm{a}} p$ value $<0.001 ;{ }^{\mathrm{b}} p$ value between 0.001 and $0.01 ;{ }^{\mathrm{c}} p$ value between 0.01 and 0.05 .

\section{- Biocontrol activity}

Fusarium sp., Rhizoctonia sp. and Pythium sp. infect pea crops leading to Fusarium root or stem rot, Rhizoctonia seedling blight and Pythium root rot respectively (Xu et al., 2012). Since we found that the endophytic strains LS.B11 and EF.B3 could control the phytopathogenic fungi in vitro, we examined whether they could rescue the effects of fungal infection using pea seedlings as a model. As expected, fungal (Fusarium sp., Rhizoctonia sp., Pythium sp. and Alternaria sp.) treatment inhibited root growth in all cases, as compared to the untreated control. Fungal treatment also produced prominent defects in root formation. Infection with Fusarium caused an $\sim 3$ fold decrease in the root length and an $\sim 4$ fold decrease in the formation of side roots (Table 2, row 4 vs. 1). When LS.B11 or EF.B3 was applied along with Fusarium sp., the decreases in root length and number of side roots were rescued (Table 2, row 4 vs. 5-6). Similarly, Pythium sp., Rhizoctonia sp., and Alternaria sp. drastically affected the formation of roots and the number of side roots (Table 2, rows 1 vs. 7,10,13). In these cases too, LS.B11 and EF.B3 were able to rescue the defects in root formation (Table 2). These results are in agreement with our finding that both endophytes could con- trol fungal growth in the in vitro assay (Figure 2). Our results strongly implicate the role of LS.B11 and EF.B3 as biocontrol agents. Moreover, the biocontrol activity exhibited by both these strains suggests they may synthesize and secrete some beneficial bioactive compounds. As reported earlier, the antimicrobial bioactive compounds could be the result of the expression of the PKS or NRPS genes (Miller et al., 2012). Therefore, we further analyzed the presence of these genes by using degenerate primers made against the conserved regions of PKS or NRPS genes.

\subsubsection{Identification of PKS and NRPS genes in LS.B11 and EF.B3}

We further tested whether the LS.B11 and EF.B3 strains, isolated from medicinal plants, have the potential to produce bioactive compounds by analyzing the presence of genes coding for NRPS and PKS (Miller et al., 2012). We tested this idea by amplifying the regions coding for the conserved domains of PKS and NRPS - the KS domain and A domain, respectively. By using degenerate primers for the A domain of NRPS, we found 1,000 bp amplicons using the genomic DNA from LS.B11, 
but not with the genomic DNA from EF.B3. The amplicons were cloned in the pGEM-T vector and The amplicons were cloned in the pGEM-T vector and sequenced and the resulting sequence was then analyzed by BLAST-N. Analysis revealed that the DNA sequence from LS.B11 was 99\% similar to the A domain of the PvdD gene of Pseudomonas aeruginosa LESB58 (Sequence ID - FM209186). The $P v d D$ gene of LESB58 has been shown to play a role in siderophore production (Mossialos et al., 2002). Similarly, using degenerate primers for the KS domain of PKS, amplicons of $\sim 650 \mathrm{bp}$ were amplified from the genomic DNA from EF.B3. The DNA sequence of the amplicon showed $71 \%$ homology with DNA coding for the beta-ketoacyl synthase gene of Burkholderia gladioli BSR3 chromosome 1 (Sequence ID - CP002599). The nucleotide sequences of the A domain of the NRPS gene in LS.B11 and the KS domain of the PKS gene in EF.B3 were submitted to GenBank with accession numbers KM225659 and KM225660, respectively. These results enabled us to hypothesize that, based on their genetic content, both the LS.B11 and EF.B3 strains are capable of producing bioactive compounds (Miller et al., 2012).

We went on to further characterize the strains by sequencing their 16S rRNA genes. The 16S rRNA gene sequence of LS.B11 was found to be $100 \%$ homologous to the 16S rRNA gene from Pseudomonas aeruginosa strain hqd-01 (Sequence ID: KC959478). On the other hand, the 16S rRNA gene sequence of EF.B3 showed $100 \%$ similarity with the 16S rRNA gene from Burkholderia gladioli pv. gladioli strain CFBP 2427 (Sequence ID: NR_117553). The 16S rRNA gene sequences of LS.B11 and EF.B3 were deposited in GenBank with accession numbers KM203877 and KM203878, respectively. We further investigated the homology of the A and KS domain. The deduced amino acid sequence of the A domain of LS.B11 and the KS domain of EF.B3 were used in the construction of phylogenies by constructing the tree using previously reported bacterial KS and A domains (Miller et al., 2012). The sequence of domain of LS.B11 is closely related to pyoverdine A synthetase of Pseudomonas fluorescens (Accession no - AAF40219) (Figure 3) which has been shown to be involved in siderophore production (Mossialos et al., 2002, Brader et al., 2014). On the other hand, the phylogenetic tree for the KS domain of EF.B3 revealed that it is closely related to microcystin synthase from Microcyctis aeruginosa (Accession no - AAF00958) (Figure 4). These results suggest that both genes could be involved in the biosynthesis of bioactive compounds.

\subsubsection{Endophytic nature of bacterial strains}

Further, we tested the endophytic nature of the bacterial strains using pea seedlings. Pea seedlings were treated with EF.B3 and LS.B11 and, after surface sterilization of their plant parts, endophytes were extracted from the roots and stems. We observed colonization firstly in the roots $24 \mathrm{~h}$ after incubating seedwith LS.B11 or EF.B3 $\left(1.2 \times 10^{4}\right.$ or $2.1 \times 10^{3} \mathrm{CFUs} / \mathrm{g}$ of root, respectively). Colonization of both bacteria increased significantly up to the day 8 (Figure $5 \mathrm{a}-\mathrm{b}$ ). Although we did observe some colonies in the untreated seeds, their number did not increase until day 8 . Interestingly, we also found colonization of both endophytes in the stem (LS.B11: $1.6 \times 10^{3}$ and EF.B3: $2.1 \mathrm{x}$ $10^{4} \mathrm{CFUs} / \mathrm{g}$ of stem) (Figure $5 \mathrm{c}-\mathrm{d}$ ). At day 8 we found better colonization of both root and stem by LS.B11 as compared to EF.B3. No colonies were observed from the water collected from the last wash during surface sterilization of treated seeds or their root or stem. The isolated colonies were checked for phosphate solubilization and all 100 colonies tested showed phosphate solubilization similar to their treated strain. 


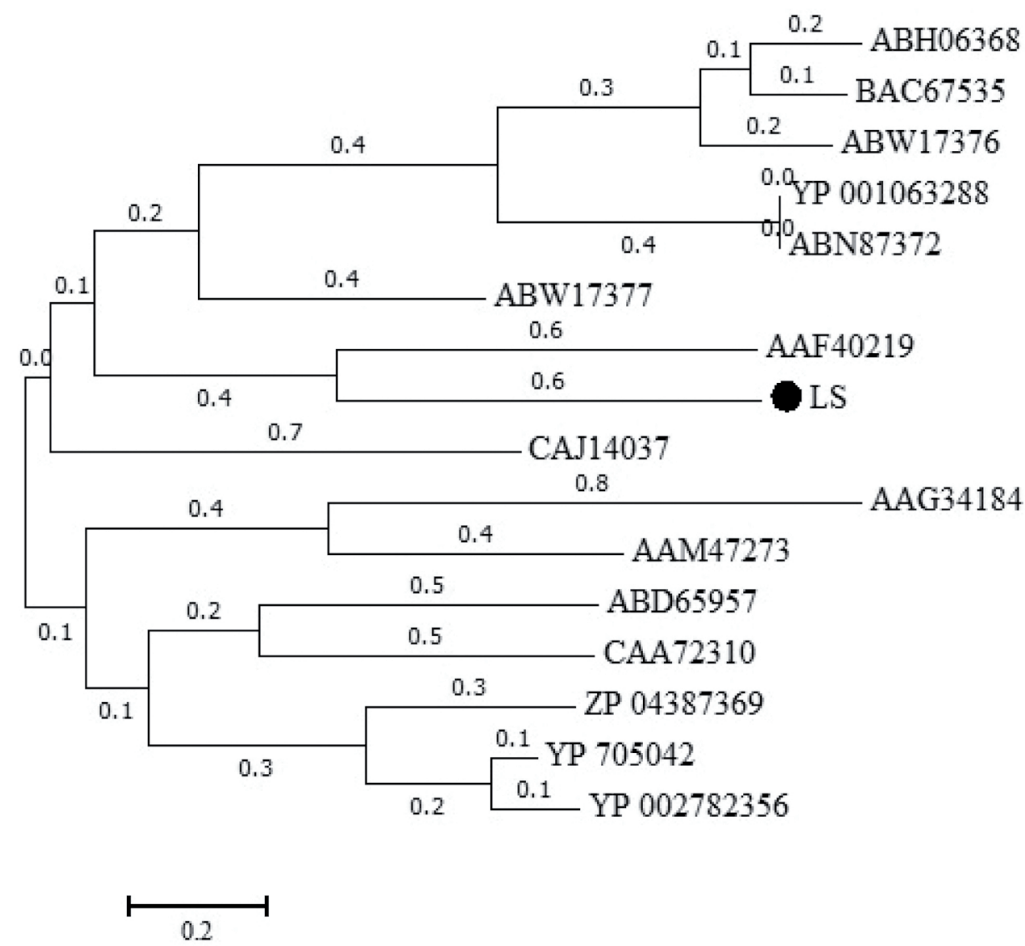

Figure 3. Phylogenetic analysis of NRPS in bacterial endophytes. Relationships were inferred by maximum likelihood analysis of the bacterial NRPS A domain. Branch length indicates inferred divergence of amino acids. The scale bar represents a change in 0.2 amino acid.

We did not observe phosphate solubilization activity in the strains isolated from untreated seeds. Furthermore, genomic DNA was isolated from strains and RAPD was performed. RAPD analysis showed that the banding pattern of inoculated strains and re-isolated strain were identical in EF.B3 (Figure 5e) and LS.B11 (Figure 5f). Burkholderia vietnamiensis and Pseudomonas fluorescens MTCC9768, which were used as negative controls, showed a different pattern of RAPD as compared to LS.B11 and EF.B3 (Figure 5e-f). 


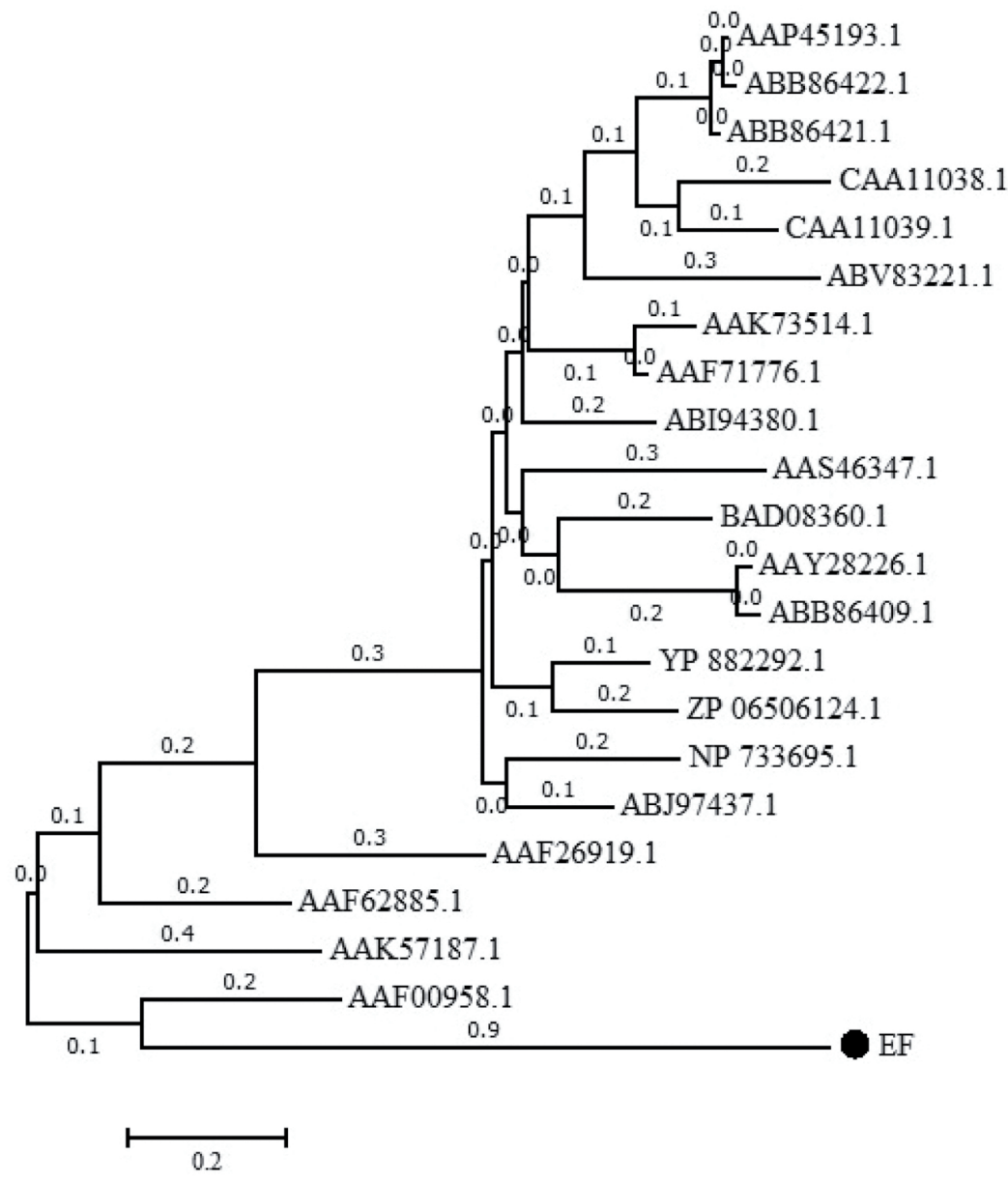

Figure 4. Phylogeny of bacterial PKS. Evolutionary relationships were determined by maximum likelihood analysis of the bacterial PKS ketosynthase domain. Branch length indicates divergence in amino acids. The scale bar represents 0.05 amino acid changes. 
(a)

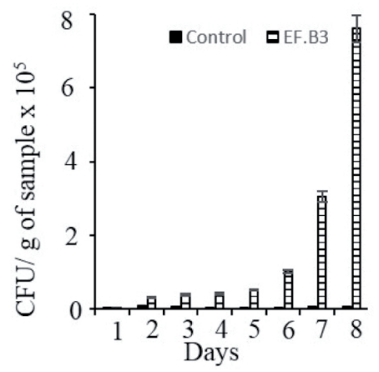

(c)

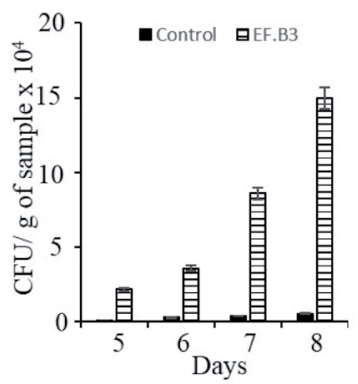

(e)

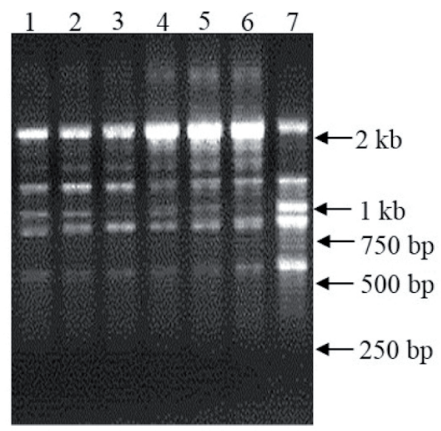

(b)

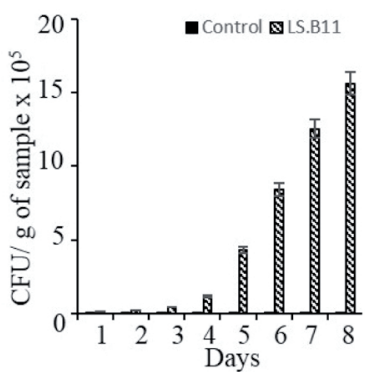

(d)

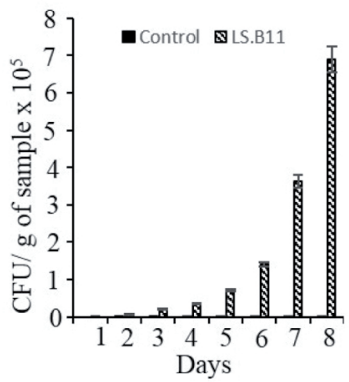

(f)

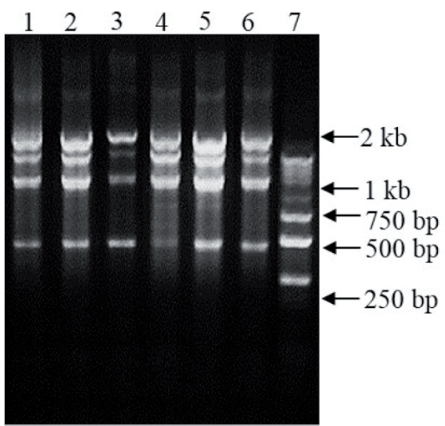

Figure 5. EF.B3 and LS.B11 are endophytic in nature. (a-d) Pea seedlings were treated with EF.B3 (a and c) or LS.B11 (b and d). Endophytes were isolated from the roots $(a-b)$ and stems (c-d). CFUs per $g$ of plant part are plotted against number of days of incubation after treatment. Untreated seeds were also analyzed and CFUs are plotted as control. (e) RAPD analysis of strains isolated in a and c. Genomic DNA was isolated from strains obtained in a and $\mathrm{c}$, and were subjected to RAPD analysis using random primers. The amplicons were resolved on an agarose gel. Lanes 1-2 depict amplicons from RAPD PCR of strains isolated from root, lanes 3-5 from stem, lane 6 EF.B3 and lane 7 Burkholderia vietnamiensis as a negative control. (f) RAPD analysis of strains isolated in $b$ and $d$. Experiment was performed as described in (e) for strains obtained in (b) and (d) except lanes 1-2 depict amplicons from RAPD PCR of strains isolated from root, lanes 3-5 from stem, lane 6 LS.B11 and lane 7 Pseudomonas fluorescens MTCC9768 as a negative control. 


\section{Discussion}

Plants provide vast and diverse niches for endophytic organisms that participate in plant growth promotion or in the production of beneficial secondary metabolites. In the present study, we isolated endophytic bacteria from the medicinal plants E. purpurea and $L$. japonica, commonly known as purple coneflower and honeysuckle, respectively. Both plants have ethnobotanical uses; E. purpurea has been used as a traditional medicant for immun estimulation, and for curing viral and microbial infections (Hudson, 2011) while L. japonica has been used for its antimicrobial, antiinflammatory and analgesic activities (Chen et al., 2012).

We found that endophytic bacteria isolated from the flowers of E. purpurea (strain EF.B3) and the stem of $L$. japonica (strain LS.B11) could have a symbiotic association with the host plants. Their endophytic nature was confirmed using pea seedlings as a model system. Both strains were able to colonize the roots and shoots of plants without hampering plant growth. In fact, LS.B11 and EF.B3 exhibited promising biofertilizer and biocontrol activities in both in vitro and in plantae experiments that account for their plant growth promotion traits. To the best of our knowledge, this is the first report of the isolation and characterization of bacterial endophytes from the petals of E. purpurea flower and stems of L. japonica.

Most soils contain insoluble phosphates which limit the availability of phosphate for utilization by plants. The ability of bacteria to solubilize mineral phosphates has been of interest to agricultural microbiologists as it enhances the availability of inorganic phosphate for plant growth (Quan et al., 2001). Therefore, we first tested the phosphate solubilizing ability of the endophytic strains. We found that EF.B3 exhibited a greater potential for phosphate solubilization, both from inorganic and organic sources, as compared to LS.B11. Nevertheles, the phosphate solubilizing activity of both the isolated strains was comparable to the previously isolated endophytic strains Exiguobacterium sp. M2N2c and $\mathrm{B} 1 \mathrm{~N} 2 \mathrm{~b}$, which were able to produce organic acid and solubilize phosphate (Rajendran et al., 2011). Secondly, we tested LS.B11 and EF.B3 for their ability to fix atmospheric nitrogen. Since plants are unable to take atmospheric nitrogen directly, endophytes may help by fixing atmospheric nitrogen and providing it to the plants (Santi et al., 2013). We found that LS.B11 and EF.B3 could grow on media lacking nitrogen (Figure $1 \mathrm{~b}$ ) thus providing evidence that both were able to fix atmospheric nitrogen and convert it into ammonia (as both strains could also produce ammonia) that can be utilized by the plants. Previously, N2-fixing isolates of Burkholderia spp. were recovered from maize and teosinte plants grown in Mexico, as well as from sugarcane plants cultivated in Brazil and South Africa (Reis et al., 2004). Thirdly, we found that both strains were able to produce IAA. Since both strains were also able to colonize roots (Figure 5), it is possible that their IAA production ability could enhance root growth as proposed by Luvizotto et al. (2010). Taken together, the biofertilizer ability of the endophyte strains LS.B11 and EF.B3 could assist in the promotion of plant growth.

In addition to biofertilizer activities, we also tested LS.B11 and EF.B3 for biocontrol traits. We found that both strains were able to produce siderophores, which is another important trait of endophytes that may indirectly influence plant growth (Rosenblueth and Romero, 2006). Siderophores form bonds with the available form of iron $\mathrm{Fe}^{3+}$, thus making it unavailable to phytopathogens and protecting plant health (Siddiqui, 2005). Additionally, endophytes exert a protective mechanism for host plants by releasing $\mathrm{HCN}$ which is lethal to phytopathogens. HCN impairs the function of the $\mathrm{Fe}$-containing heme group of cytochrome oxidase and other respiratory enzymes, resulting into cell death. 
We found that both LS.B11 and EF.B3 could produce HCN. The presence of biofertilizer and biocontrol activities in both endophyte strains led us to test these activities in plantae.

Since it was difficult to measure plant growth promotion activities in E. purpurea and L. japonica, we used pea seedlings as a model to analyze the effects of endophytes on plant growth. Seed bacterialization of pea seedlings with LS.B11 and EF.B3 promoted their root and shoot lengths and increased the number of lateral roots. These increases could be correlated with the ability of the strains to produce IAA and efficiently fix nitrogen. Additionally, both strains were able to control the growth of phytopathogens as demonstrated by in vitro and in plantae experiments. Both strains suppressed the growth of Fusarium sp., Pythium sp., Rhizoctonia sp. and Alternaria sp. in vitro, and also rescued their injurious effects on plant seedlings. It is possible that LS.B11 and EF.B3 could rescue the deleterious effects of fungi on plant seedlings by producing siderophores or HCN. As previously reported, Clonostachys rosea ACM941 is an effective bioagent that controls soilborne Fusarium oxysporum f. sp. pisi, Fusarium. solani f. sp. pisi, Mycosphaerella pinodes, Rhizoctonia solani, and Sclerotinia sclerotiorum pathogens, which cause root rot complex in field peas, and increased both the emergence and yield against these pathogens (Xue, 2003). Since E. purpurea and L. japonica plants are affected by many fungal pathogens (Waipara et al., 2007), we suggest that treatment with LS.B11 and EF.B3 could be used to control these fungal pathogens.

The endophytic bacterial isolates were characterized using 16S rRNA gene sequencing, which revealed that LS.B11 and EF.B3 belong to the Pseudomonas aeruginosa and Burkholderia gladioli, respectively. Members of Pseudomonas sp. and Burkholderia sp. have been previously shown to confer growth promoting abilities to plants and were shown to increase the productivity of a wide variety of crops (Oteino et al., 2015; Devi et al., 2015, Sharma et al., 2014 and Castanheira et al., 2016).

Favaro et al. (2012) investigated the antagonistic potential of the sugarcane endophytic Epicoccum nigrum P16 strain against Ceratocyctis. paradoxa and Fusarium verticillioides, which reduce radial growth by more than $50 \%$, which indicates that diffusible compounds were released in the culture medium by the antagonistic endophyte. We also performed genetic analysis of LS.B11 and EF.B3 to assess their potential to synthesize bioactive compound(s) for controlling phytopathogens. The genomic DNA of LS.B11 and EF.B3 was tested for the presence of the NRPS and PKS genes using degenerate primers designed against the conserved regions present in these genes. Interestingly, the NRPS gene was found to be associated with LS.B11, and showed 99\% homology with the $p v d \mathrm{D}$ gene of $P$. aeruginosa, while the PKS gene was found to be associated with EF.B3, and showed 71\% homology with the PKS of B. gladioli (Miller et al., 2012). Our findings demonstrate that the LS.B11 and EF.B3 strains could be directly or indirectly involved in promoting plant growth. Both strains should be tested further for their performance at the field level and should be further explored to identify the expression of bioactive compounds conferring biocontrol activity.

\section{Conclusion}

In conclusion, this study revealed that the use of EF.B3 and LS.B11 as plant growth promoting bacteria improved the plant growth and nutrient uptake, and showed a significant increase in peaseedling growth. Thus inoculation of nutrient deficient soils with these endophytes could be beneficial for nutrient management and could reduce the burden of applying chemical fertilizers. Moreover, both endophytes have a great potential for controlling phytopathogens of 
fungal origin and thus their usage as biocontrol agents could also decrease the need to use harmful fungicides. However, these applications needs to be further evaluated at the field level. Due to the presence of biosynthetic genes in these endophytes, a thorough study is required to isolate and identify the bioactive compounds they may produce.

\section{Acknowledgements}

This project was conducted in part as the collaboration between Shoolini University of Biotechnology and Management Sciences, Solan H.P. and CSIRInstitute of Microbial Technology, Chandigarh, India. This work was supported by FAST-track grant of Department of Science and Technology (DST) (grant: SR/FT/LS-108/2012) to AKS. The work was partly supported by a Ramalingaswami Re-entry Fellowship to DKS (Grant:BT/RLF/RE-ENTRY-33-2010) by Department of Biotechnology (DBT), India.

Conflict of Interest Statement: No conflict of interest

\section{References}

Ahmad, F., Ahmad, I., Khan, M. S. 2008. Screening of free-living rhizospheric bacteria for their multiple plant growth promoting activities. Microbiol. Res. 163, 173-181.

Alvin, A., Miller, K. I., Neilan, B.A. 2014. Exploring the potential of endophytes from medicinal plants as sources of antimycobacterial compounds. Microbiol. Res. 169, 483-495.

Brader, G., Compant, S., Mitter, B., Trognitz, F., Sessitsch, A. 2014. Metabolic potential of endophytic bacteria. Curr. Opin. Biotech. 27, 30-37.

Castanheira, N., Dourado, A.C., Kruz, S., Alves, P. I.L., Delgado-Rodriguez, A., Pais, I., Semedo, J., Scotti-Campos, P., Sanchez, C., Borges, N., Carv- alho, G., Barreto Crespo, M.T., Fareleira, P. 2016. Plant growth-promoting Burkholderia species isolated from annual ryegrass in Portuguese soils. J. Appl. Microbiol. 120, 724-739.

Chen, W. C., Liou, S.S., Tzeng, T. F., Lee, S. L., Liu, I.M. 2012. Wound repair and anti-inflammatory potential of Lonicera japonica in excision wound-induced rats. BMC Complement. Altern. Med. 12, 226.

Devi, U., Khatri, I., Saini, R.V., Kumar, L., Singh, D., Kumar, N., Garriz, A., Subromanian, S., Sharma, D., Saini, A.K. 2015. Genomic and functional characterization of a novel Burkholderia sp.strain AU4i from pea rhizosphere conferring plant growth promoting activities. Adv. Genet. Eng. 4, 129.

Etesami, H., Mirsyed Hosseini, H., Alikhani, H.A. 2014. In planta selection of plant growth promoting endophytic bacteria for rice (Oryza sativa L.). J. Soil Sci. Plant. Nutr. 14, 491-503.

Favaro, L.C.L., Sebastianes, F.L.S., Araujo, W.L. 2012. Epicoccum nigrum P16, a sugarcane endophyte, produces antifungal compounds and induces root growth. PLoS ONE. 7, e36826.

Hardoim, P.R., Van Overbeek, L.S., Elsas, J.D.V. 2008. Properties of bacterial endophytes and their proposed role in plant growth. Trends Microbiol. $16,463-471$.

Hudson, J.B. 2011. Applications of the phytomedicine Echinacea purpurea (Purple Coneflower) in infectious diseases. J. Biomed. Biotechnol. 2012, 1-16.

Hurek, R.B., Hurek, T. 2011. Living inside plants: bacterial endophytes. Curr. Opin. Plant Biol. 14, 435-443.

Kang, Hoon, S., Cho, H.S., Cheong, H., Ryu, C.M., Kim, J.F., Park, S.H. 2007. Two bacterial entophytes eliciting both plant growth promotion and plant defense on pepper (Capsicum annuum L.). J. Microbiol. Biotechnol. 17, 96-103. 
Keller, N. P., Turner, G., Bennett, JW. 2005. Fungal secondary metabolism - from biochemistry to genomics. Nat. Rev. Microbiol. 3, 937-947.

Loper, J.E., Buyer, J.S. 1991. Siderophores in microbial interactions on plant surfaces. Mol. Plant Microbe Interact. 4,5-13.

Luvizotto, D.M., Marcon, J., Andreote, F.D., DiniAndreote, F., Neves, A.A.C., Araujo, W.L., Pizzirani-Kleiner, A. A. 2010. Genetic diversity and plant-growth related features of Burkholderia spp. from sugarcane roots. World J. Microbiol. Biotechnol. 26, 1829-1836.

Miller, K.I., Qing, C., Sze, D.M.Y., Neilan, B.A. 2012. Investigation of the biosynthetic potential of endophytes in traditional chinese anticancer herbs. PLoS One. 7,e35953.

Mossialos, D., Ochsner, U., Baysse, C., Chablain, P., Pimay, J.P., Koedam, N., Budzikiewicz, H., Fernandez, D.U., Schafer, M., Ravel, J., Cornelis, P. 2002. Identification of new, conserved, nonribosomal peptide synthetases from fluorescent pseudomonads involved in the biosynthesis of the siderophore pyoverdine. Mol. Microbiol. 45, 1673-1685.

Oteino, N., Lally, R.D., Kiwanuka, S., Lloyd, A., Ryan, D., Germaine, K.J., Dowling, D.N. 2015. Plant growth promotion induced by phosphate solubilizing endophytic Pseudomonas isolates. Front. Microbiol. 6, 745.

Quan, C., Zhang, L., Wang, Y., Ohta, Y. 2001. Production of phytase in a low phosphate medium by a novel yeast Candida krusei. J. Biosci. Bioeng. 92, $154-160$.

Rajendran, G., Patel, M.H., Joshi, S.J. 2011. Isolation and characterization of nodule-associated Exiguobacterium sp. from the root nodules of fenugreek (Trigonella foenum-graecum) and their possible role in plant growth promotion. Int. J. Microbiol. 2012, 1-8.
Reis, V.M., Estrada-de los Santos, P., Tenorio-Salgado, S., Vogel, J., Stoffels, M., Guyon, S., Mavingui, P., Baldani, V.L., Schmid, M., Baldani, J.I., Balandreau, J., Hartmann, A., Caballero-Mellado, J. 2004. Burkholderia tropica sp. nov., a novel nitrogen fixing, plant associated bacterium. Int. J. Syst. Evol. Microbiol. 54, 2155-2162.

Rosenblueth, M.,Romero, E.M. 2006. Bacterial endophytes and their interactions with hosts. Mol. Plant Microbe Interact. 19, 827-837.

Santi, C., Bogusz, D., Franche, C. 2013. Biological nitrogen fixation in non-legume plants. Ann. Bot. 1-25.

Schwyn, B., Neilands, J. B. 1987. Universal chemical assay for the detection and determination of siderophores. Anal. Biochem. 160, 47-56.

Sharma, A., Shankhdhar, D., Sharma, A., Shankhdhar, S. C. 2014. Growth promotion of the rice genotypes by PGPRs isolated from rice rhizosphere. J. Soil Sci. Plant Nutr. 14, 505-517.

Siddiqui, Z.A. 2005. PGPR: prospective biocontrol agents of plant pathogens. In: Siddiqui ZA (ed) PGPR: biocontrol and biofertilization. Springer, The Netherlands, 111-142 p.

Trivedi, P., Spann, T., Wang, N. 2011. Isolation and characterization of beneficial bacteria associated with citrus roots in Florida. Microb. Ecol. 62, 324-336.

Waipara, N.W., Winks, C.J.,Smith, L. A., Wilkie, J.P. 2007. Natural enemies of Japanese honeysuckle, Lonicera japonica, in New Zealand. N. Z. Plant Prot. 60,158-163.

Xu, L., Ravnskov, S., Larsen, J., Nicolaisen, M. 2012. Linking fungal communities in roots, rhizosphere, and soil to the health status of Pisum sativum. FEMS Microbiol. Ecol. 82, 736-745.

Xue, A.G. 2003. Biological control of pathogens causing root rot complex in field pea using Clonostachys rosea strain ACM941. Phytopathology. 93, 329-335. 